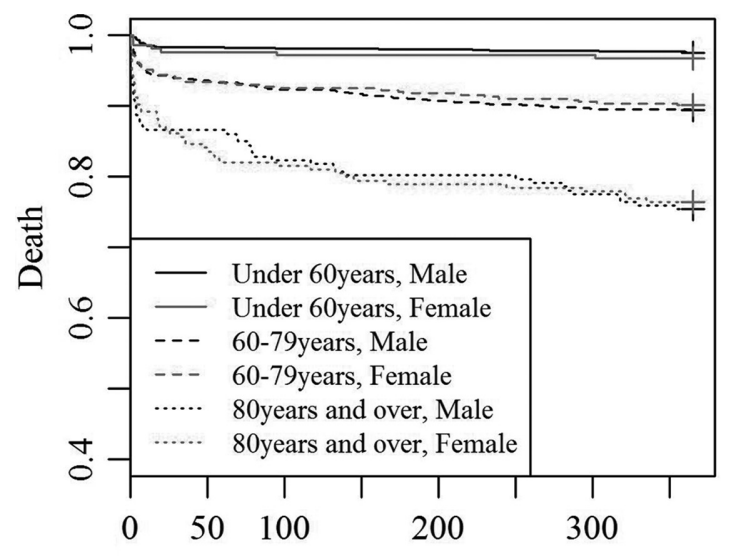

Number of days since symptom onset

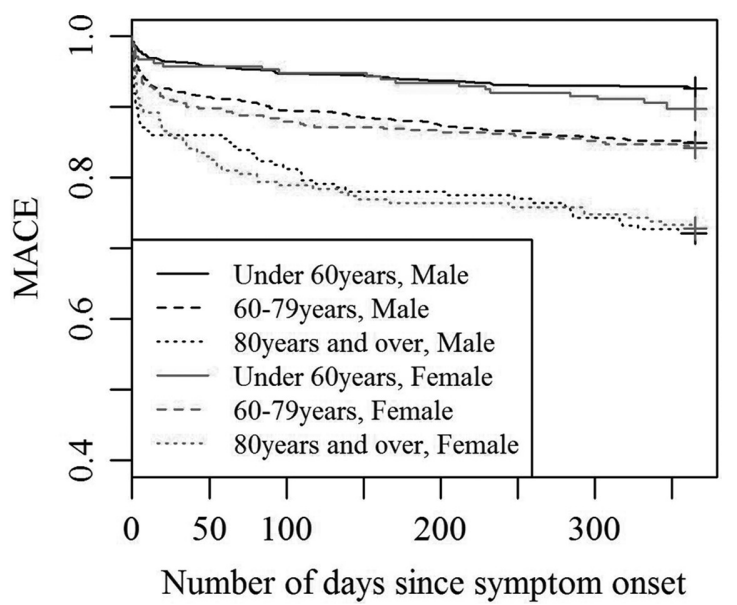

Number of days since symptom onset

Abstract 26 Figure 2 Kaplan-Meier survival curves comparing age-adjusted mortality and MACE in females and males

mortality or MACE between genders (Table 2, Figure 2). Age directly correlated with total mortality and MACE. Comparison between the three age tertiles showed Group 2 was associated with a higher rate of death (HR 4.17, 95\% CI 2.866.09) and MACE (HR 2.03, 95\% CI 1.60-2.57) at $12 \mathrm{~m}$ compared to Group 1. The highest rate of death (HR 10.53, 95\% CI 7.07-15.67) and MACE (HR 3.93, 95\% CI 2.995.17) was seen in Group 3.

Conclusion This large retrospective study has shown that whilst women appear to have significantly higher rates of death and MACE compared to men, when adjusted for age, gender was not associated with a statistically significant difference in outcomes. The difference in unadjusted outcomes may be due to the fact that women tend to present with STEMI at an older age than men. Therefore, the difference in outcomes is likely to be age-related rather than gender-related.

\begin{tabular}{|c|c|c|c|}
\hline Gender & Number $\mathbf{n}$ & Death $\mathbf{n}(\%)$ & MACE $n(\%)$ \\
\hline Male & 2223 & $175(7.9)$ & $276(12.4)$ \\
\hline \multirow[t]{3}{*}{ Female } & 826 & $94(11.4)$ & $140(16.9)$ \\
\hline & & $p<0.01$ & $p<0.01$ \\
\hline & & HR $1.48(1.15-1.90)$ & HR $1.40(1.14-1.72$ \\
\hline
\end{tabular}

\begin{tabular}{|c|c|c|c|}
\hline Gender and Age & Number $\mathbf{n}$ & MACE n (\%) & Death n (\%) \\
\hline Male $<60$ & 1060 & $78(7.4)$ & $26(2.5)$ \\
\hline \multirow[t]{3}{*}{ Female $<60$} & \multirow[t]{3}{*}{216} & $22(10.2)$ & $7(3.2)$ \\
\hline & & $p=0.16$ & $p=0.51$ \\
\hline & & HR $1.40(0.87-2.25)$ & HR $1.32(0.58-3.06)$ \\
\hline Male 60-79 & 976 & $146(15.0)$ & $103(10.6)$ \\
\hline \multirow[t]{3}{*}{ Female 60-79 } & \multirow[t]{3}{*}{415} & $65(15.7)$ & $41(9.9)$ \\
\hline & & $p=0.99$ & $p=0.53$ \\
\hline & & HR $1.00(0.75-1.35)$ & HR $0.89(0.62-1.28)$ \\
\hline Male $\geq 80$ & 187 & $52(27.8)$ & $46(24.6)$ \\
\hline \multirow[t]{3}{*}{ Female $\geq 80$} & \multirow[t]{3}{*}{195} & $53(27.2)$ & $46(23.6)$ \\
\hline & & $p=0.90$ & $p=0.83$ \\
\hline & & HR 0.98 (0.67-1.43) & HR 0.96 (0.64-1.44) \\
\hline
\end{tabular}

\section{IMPACT OF CULPRIT VERSUS NON-CULPRIT ANGIOGRAPHY STRATEGY ON PRIMARY PCI DOOR TO BALLOON TIMES}

Anna Horne, Julian Gunn, Javaid Iqbal, Kenny Morgan, lan Hall, John West, Ever Grech, David Barmby, Nigel Wheeldon, Robert Storey, James Richardson*. Sheffield Teaching Hospitals NHS Trust; *Presenting Author

\subsection{6/heartjnl-2016-309890.27}

Background Guidelines for ST-segment elevation myocardial infarction (STEMI) recommend primary percutaneous coronary intervention (PPCI) within $90 \mathrm{~min}$ of arrival in a PCI-capable hospital. Some PCI operators perform diagnostic angiography of the non-culprit artery prior to intervention ('non-culprit' strategy) while others proceed directly to the presumed culprit vessel ('culprit' strategy) reserving imaging of the non-culprit vessel until after the PCI. We evaluated the 'time cost' of each approach and their impact upon door to balloon times (D2B).

Methods All consecutive patients presenting with STEMI to a regional heart attack centre between April 2014 and March 2015 ( $\mathrm{n}=630$ ) were included. The time from the first angiogram acquisition (culprit or non-culprit vessel) to device use (thrombectomy catheter, balloon or stent) was recorded for each strategy. Overall D2B times were analysed.

Results A culprit strategy was followed in 69/630 and a nonculprit approach in 561/630. The mean time from first image to device use was 15 mins 41 s for non-culprit strategy and 8 mins $9 \mathrm{~s}$ for culprit strategy. The non-culprit strategy therefore incurred a delay of 7 mins $32 \mathrm{~s}(\mathrm{p}<0.01)$. The mean D2B time was 52 mins and 66 mins for the culprit and non-culprit strategies respectively $(\mathrm{p}<0.05)$. The percentage meeting D2B time $<90$ mins was $86 \%$ for culprit and $78 \%$ for nonculprit strategies. Percentage meeting D2B time $<60$ mins (which may have additional mortality benefit) was $71 \%$ and $58 \%$ for the culprit and non-culprit strategies respectively. In our cohort, mortality was significantly lower in patients with D2B $<90$ mins at $2.0 \%$, versus $4.6 \%$ in those whose D2B was $>90 \mathrm{mins}(\mathrm{p}=0.02)$.

Conclusion A 'culprit' PPCI strategy results in significantly shorter D2B times, facilitating institutional attainment of national guideline targets, which may translate into improved patient outcomes. 